\title{
Kajian Teologis Terhadap Lesbian Di Lembang Perindingan
}

\author{
Henri Sirangki dan Yefta Noval \\ Institut Agama Kristen Negeri Toraja \\ henriinthe98@gmail.com \& yeftanoval@gmail.com
}

\begin{abstract}
God created man in His image and likeness. This means that humans have a resemblance to their creator. When God created man the Bible clearly says that in the beginning God only created man, male and female. Then God made man as his mandate on earth in order to develop and conquer the earth. However, recently there has been an issue about LGBT, especially lesbians, who are pro and contra in the community. For some people there are those who accept the lesbian behavior and there are also those who reject the behavior. Such behavior is not only carried out by non-Christian people but such behavior has also been carried out by those who have held the status of believers in God, even though the Bible clearly opposes such behavior because it is contrary to God's purpose and purpose in creating humans as male and female. female. On that basis it can be said that those who become lesbian perpetrators are not only against their human nature but also against God's decree. Humans can only fulfill God's purpose of creating them in being mandatory over the whole creation if humans have contact with the opposite sex instead of the same sex. Keywords: Lesbian, Same Sex, Nature, Theology
\end{abstract}

\begin{abstract}
Abstrak
Allah menciptakan manusia menurut gambar dan rupa-Nya. Ini berarti manusia memiliki keserupaan dengan penciptanya. Ketika Allah menciptakan manusia Alkitab dengan jelas mengatakan bahwa Allah pada mulanya hanya menciptakan manusia yakni laki-laki dan perempuan. Lalu kemudian Allah menjadikan manusia sebagai mandatarisnya di bumi agar berkembang dan menaklukkan bumi. Namun belakangan mencuat isu tentang LGBT khususnya lesbian yang pro kontra di tengah masyarakat. Bagi Sebagian orang ada yang menerima perilaku lesbian tersebut dan ada juga yang menolak perilaku tersebut. Perilaku demikian tidak hanya dilakukan oleh orang-orang yang nonkristen tetapi perilaku
\end{abstract}


demikian juga telah dilakukan oleh mereka yang telah menyandang status sebagai orang percaya kepada Allah, padahal Alkitab dengan jelas menentang perilaku demikian karena bertentangan dengan tujuan dan maksud Allah menciptakan manusia sebagai laki-laki dan perempuan. Atas dasar itu bisa dikatakan bahwa mereka yang menjadi pelaku lesbian bukan hanya menentang kodratnya sebagai manusia tetapi juga menentang ketetapan Allah. Manusia hanya dapat menuruti tujuan Allah menciptakan mereka dalam menjadi mandataris atas seluruh ciptaan jika manusia berhubungan dengan lawan jenisnya bukan sesama jenis.

Kata Kunci: Lesbian, Sesama Jenis, Kodrat, Teologis

\section{Pendahuluan}

Manusia merupakan ciptaan Allah yang paling mulia dimana manusia memiliki keistimewaan (Privilese) dibandingkan ciptaan lain. sejak penciptaan, Allah telah menciptakan manusia yakni laki-laki dan perempuan dengan tujuan agar mereka bisa hidup bersama dan bertambah banyak hingga memenuhi bumi (Kej. 1:27-28). dari sini jelaslah bahwa Allah menciptakan laki-laki dan perempuan (berpasangan) menurut gambar dan rupa Allah sebagai makhluk sosial yang dapat memenuhi bumi dan meneruskan perintah dari Allah. namun belakangan ini muncul isu yang menjadi perbincangan hangat seperti pernikahan sejenis, ketertarikan kepada sesama jenis dan transgender atau yang dikenal dengan istilah LGBT (Lesbian Gay Biseksual Transgender). oleh karena itu penulis tertarik untuk mengkaji isu ini terlebih khusus pada kasus lesbian yang terjadi di lingkungan lembang Perindingan.

Penulis melihat bahwa perilaku lesbian merupakan perilaku yang bertentangan dengan nilai-nilai moral dalam masyrakat terlebih khusus bertentangan dengan Firman Allah seperti yang dikemukakan di atas. penulis juga melihat jika perilaku-perilaku seperti ini terus terjadi dalam masyarakat secara khusus di lembang Perindingan akan berdampak pada rusaknya tatanan moral dalam masyarakat dan semakin menjerumuskan pelaku ke dalam dosa, sebab perilaku demikian jelas bertentangan dengan ketetapan Allah. selain berdampak pada si pelaku tersebut, perilaku tersebut juga membahayakan masyarakat apabila individu tidak mau menikah dan memilih untuk melampiaskan nafsunya secara 
ilegal, menyimpang dan terlarang akibatnya merusak sistem kekeluargaan dan merapukan landasan kemasyarakatan, menimbulkan kehancuran akhlak dan merenggangkan ikatan nilai-nilai dan norma agama sehingga pada akhirnya membawa kebebasan tanpa batas. ${ }^{1}$

\section{Metode Penelitian}

Dalam mengkaji kasus ini penulis secara umum melakukan pendekatan melalui pengamatan terhadap perilaku Lesbian tersebut dan juga menggunakan metode kualitatif dalam mengumpulkan data. oleh karena itu Penulis hendak mengungkapkan bahwa perilaku Lesbian adalah dosa karena melawan ketetapan Allah dalam tujuan semulanya menciptakan manusia.

\section{Hasil dan Pembahasan}

\section{Definisi Lesbian}

Menurut Kamus Besar Bahasa Indonesia (KBBI), lesbian adalah wanita yang mencintai atau merasakan rangsangan seksual sesama jenisnya; wanita homoseks. Menurut Novika dalam jurnalnya mengenai "Kontruksi Sosial Tentang Lesbian", lesbian merupakan perempuan yang memiliki ikatan emosional dan yang melihat dirinya sebagai bagian dari sebuah komunitas lesbian serta memiliki ikatan baik itu emosional ataupun seksual dengan perempuan. Selanjutnya dia mengungkapkan bahwa perilaku lesbian mengacu pada sebuah hubungan emosional yang melibatkan rasa, cinta kasih sayang antara dua manusia yang memilki jenis kelamin perempuan. ${ }^{2}$ Menurut para ahli (Sadarjoen) lesbian adalah istilah yang dipakai untuk menyebut seseorang yang tampil berkenaan dengan seks yang menimbulkan rangsangan (erotik), psikologi dan emosional yang mana minat sosialnya tertuju pada sesama jenis. Lesbian adalah daya tarik erotis yang justru kuat tertarik pada sesama jenis. ${ }^{3}$ Ricch, Mengungkapkan lesbi adallah sebutan untuk menyebut homoseksual perempuan atau perempuan yang memiliki hasrat seksual atau emosi kepada sesama perempuan lainnya.

Dari penjelasan di atas dapat ditarik kesimpulan bahwa lesbian adalah tindakan erotik, emosional dan psikologi dari seorang perempuan yang menaru minat pada sesama

\footnotetext{
${ }^{1}$ Safrudin, Aziz. "Pendidikan Seks Perspektif Terapi Sufistik Bagi LGBT". Ernest: 2017. Hal 4.

${ }^{2}$ Sandra, Novika Lusia. Jurnal "Kontruksi Sosial Tentang Lesbian (2018). Hal. 10-13

${ }^{3}$ https://www.geogle.com/search?q=pengertian+lesbian+menurut+para+ahli\&oq=pengertian+lesbian+para+ahli\&a qs=chrome..69i57.7774j0j4\&client=ms-android-xiaomi\&sourceid=chrome-mobile\&ie=UTF-8. Di akses 28 April 2021.
} 
jenisnya (perempuan). Konkretnya, lesbian adalah perempuan yang mempunyai rasa ketertarikan atau punya rangsangan seksual terhadap sesama jenisnya (perempuan).

\section{Kelompok Lesbian}

Terdapat tiga label yang muncul dalam kelompok lesbian berdasarkan karakter dasar dari perempuan tersebut atau penampilan keseharian pada seorang lesbian yaitu:

1. Butch (B)

Jenis kelompok ini lebih mengacu pada kelompok lesbian yang memiliki karakter tomboi, kelaki-lakian, berbusana dan bersikap maskulin, hal ini dapat dilihat dengan cara berpakaian persis sama dengan laki-laki pada umumnya seperti memakai kemeja laki-laki, potongan rambut dan sikap yang cenderung gentle/minly

2. Femme (F)

Merupakan seorang lesbian yang berkarakteristik feminism, bersikap lembut layaknya perempuan heteroseksual pada umumnya yang tidak dapat menampakkkan ciri seksual sama sekali. Femme terlihat cenderung menggunakan pakaian gaun perempuan, anggun, feminim, cantik, selalu menjaga sikap seperti pada umumnya perempuan.

3. Andro (A)

Jenis ini merupakan perpaduan penampilan antara butch dan femme. Lesbian ini cenderung memiliki karakter yang fleksibel, terkadang bisa bergaya tomboi namun tetap terlihat feminimnya, tidak risih saat berdandan dan menggunakan makeup dan menata rambut dengan gaya feminism. Kelompok lesbian ini dalam relasi seksualnya dapat menyesuaikan saat bertemu kelompok butch ia akan menjadi femme dan sebaliknya. ${ }^{4}$

Berdasarkan pengamatan yang dilakukan penulis di lapangan kasus lesbian yang terjadi di lembang Perindingan termasuk dalam kelompok lesbian butch (B). sebab dari pengamatan yang dilakukan, individu tersebut dalam kesehariannya memang berperilaku seperti laki-laki pada umumnya, mulai dari pakaian, potongngan rambut dan sikap/perilaku.

\footnotetext{
${ }^{4}$ Sandra, Novika Lusia. Jurnal "Kontruksi Sosial Tentang Lesbian (2018). Hal. 11
} 


\section{Pandangan-Pandangan Masyarakat dan Tokoh Agama Mengenai Perilaku Lesbian di Lembang Perindingan}

Penelitian dilakukan di Lembang Perindingan Kecamatan Gandangbatu Sillanan Kabupaten Tana Toraja Provinsi Sulawesi-Selatan dilakukan dengan menggunakan metode observasi dan wawancara. Pelaku lesbian adalah seorang perempuan yang berinisial HS berumur sekitar 23 tahun merupakan anak ke-enam dari delapan bersaudara yang merupakan pasangan dari bapak inisial LM dan ibu inisial PP. Dalam keseharian pelaku memang tampak berbeda dari saudara-saudara perempuan yang lain dan perempuan pada umumnya, termasuk dalam penampilan dan perilaku yang mana cenderung mirip dengan laki-laki. Penampilan dan perilaku yang dinampakkan HS dinampakkan secara terangterangan seolah-olah hal tersebut adalah sesuatu yang biasa saja dan seolah tidak ada yang salah dengan dirinya. Salah satu contoh ketika pelaku dipanggil oleh keluarga atau masyarakat sekitar dengan sebutan laki-laki yaitu so', HS tidak merasa canggung atau malu namun justru menampakkan sikap yang nyaman atau menerima sebutan itu atau panggilan itu dibandingkan jika dipanggil dengan sebutan perempuan yaitu lai'.5

a. Pandangan dari Pihak Keluarga

Menurut keluarga HS mulai menampakkan perilaku yang berbeda saat mulai duduk bangku SMP sampai sekarang. Menurut Informan DM yakni sepupu pelaku memang sejak dibangku SD sampai Sekolah Menengah, HS memang lebih banyak berinteraksi dengan laki-laki dan lebih banyak memiliki teman laki-laki disbanding perempuan. ${ }^{6}$ Keluarga juga menjelaskan bahwa perilaku HS berlanjut sampai ia duduk di bangku Perguruan Tinggi hingga sekarang. Bahkan HS sering membawa teman perempuannya ke rumah dan memperkenalkan dengan keluarga dimana HS menganggap bahwa teman perempuannya tersebut adalah pacarnya (ceweknya). Menurut keterangan dari keluarga, setiap HS ketika datang membawa pacarnya ke rumah perawakan dari pacarnya tersebut berpenampilan seperti perempuan pada umumnya yaitu feminim

\footnotetext{
${ }^{5}$ So' dalam keseharian masyarakat Toraja merupakan kata yang digunakan atau dikenakan pada laki-laki. Sedangkan lai' ungkapan atau kata yang dikenakan pada perempuan.

${ }^{6}$ Wawancara dengan DM sepupu pelaku pada tanggal 1 Mei 2021.
} 
yang dijelaskan tadi di atas tergolong dalam kelompok lesbian Femme. Ketika keluarga dimintai keterangan perihal apa yang menjadi faktor penyebab HS berperilaku seperti itu, keluarga dengan gamblang mengatakan bahwa mereka tidak tahu, keluarga hanya menjelaskan bahwa mungkin itu adalah sikap bawaan sejak lahir. Sedangkan ketika ditanya apa yang menjadi upaya dari keluarga untuk mengubah perilaku HS tersebut, keluarga juga tidak tahu harus berbuat apa kecuali memberikan nasihat kepada HS, sebab keluarga juga berharap HS bisa berubah seperti perempuan pada umunya. Keadaaan HS sekarang ini itu tidak ditolak oleh keluarga tetapi bukan berarti menyetujui sikap HS tersebut sebab keluarga mengharapkan perubahan.

b. Pandangan Masyarakat

Menurut salah satu aparat Lembang yang adalah juga ketua RT tempat dimana HS berdomisili memang perilaku yang dinampakkan oleh HS berbeda dari perempuan pada umumnya, dalam beberapa kesempatan ketika ada kegiatan dalam masyarakat HS justru lebih banyak mengerjakan pekerjaan yang dikerjakan oleh laki-laki pada umumnya. Di sisi lain HS seringkali mempublikasikan hubungan sesame jenisnya di media social dan ini dilihat oleh kelompok masyarakat seperti yang dijelaskan oleh tetangga pelaku inisial AM. Masyarakat menilai bahwa HS secara terang-terangngan terbuka dengan perilakunya. Masyarakat menilai HS ini tidak rasa canggung dengan apa yang diperlihatkan melalui media sosial. Perilaku HS melalui pengamtan penulis nampaknya merupakan hal yang biasa dalam masyarakat sebab pemerintahpun belum memberika solusi apa dan berbuat apa-apa mengenai permasalahan ini.

c. Pandangan Tokoh Agama

Penulis melakukan wawancara kepada tokoh agama dalam hal ini Pendeta Gereja Toraja tempat dimana HS berjemaat. Pendeta MBS memberikan keterangan bahwa HS memang menonjolkan sifat kelaki-lakian, hal itu Nampak ketika HS hendak menerima peneguhan sidi dimana Pendeta MBS menegaskan bahwa semua perserta sidi perempuan memakai pakaian gaun namun HS enggan menggunakannya tetapi Pendeta tersebut memaksanya untuk menggunakan gaun tersebut agar bisa diteguhkan. Dari sini Pendeta menjelaskan bahwa memang dalam diri HS melekat sikap kelaki-lakian yang kuat. Dari wawancara yang dilakukan oelh penulis, pendeta memberikan tanggapan bahwa perempuan seharusnya berpakaian atau berpenampilan seperti 
perempuan demikianpun dengan laki-laki. Pendeta juga berpendapat bahwa sudah menjadi kewajiban bagi gereja untuk mengingatkan, menegur dan membina warga gerejanya yang tidak hidup dengan ketetapan Allah. dalam hal ini pendeta juga bagaian dari Alkitab dari 1 Timotius 2:9-10 bahwa hendaklah perempuan untuk berdandan dengan pantas dengan sopan dan teratur. Ketika penulis bertanya perihal pandangan gereja mengenai perilaku lesbian pendeta dengan tegas mengatakan bahwa gereja menolak hubungan sesama jenis apalagi sampai pada pernikahan, sebab hal itu menentang ketetapan firman Allah yang menciptakan manusia secara berpasangan dengan tujuan untuk menghasilkan keturunan.

\section{Lesbian menentang kodrat manusia}

Alkitab dengan jelas mengungkapkan bahwa ketika manusia diciptakan, Allah menciptakan mereka laki-laki dan perempuan (Kej. 1:27; 2:7; Mat. 19:4). Manusia dalam keadaan individu pada umumnya tidaklah diturunkan secara sebagian-sebagian tetapi secara keseluruhan, demikianlah laki-laki dan perempuan bersama-sama disebut manusia ${ }^{7}$. Dalam hal ini jelas disebutkan bahwa manusia itu adalah laki-laki dan perempuan, manusia hanya dapat menjaga kelangsungan hidup jika laki-laki dan perempuan itu bersatu. Kodrat manusia ketika dicipta menurut jenis kelaminnya tentulah memiliki maksud dalam rencana Allah sehingga menolak kodrat yang telah Allah tetapkan atas diri kita adalah bentuk penyelewengan kepada Allah. Menolak kodrat yang melekat pada diri yang telah berikan atas dasar rencanaNya adalah bentuk ketidaktaatan kepada Allah, hendaklah dengan sepenuh hati dan penuh kesadaran menjalani hidup berdasarkan kodrat yang Allah telah berikan. Lesbian adalah perilaku yang jelas-jelas ditentang Allah seperti yang terdapat dalam Roma 1:25-27 : "Sebab mereka menggantikan kebenaran Allah dengan dusta dan memuja dan menyembah makhluk dengan melupakan Penciptanya yang harus dipuji selamalamanya,Karena itu Allah menyerahkan mereka kepada hawa nafsu yang memalukan, sebab isteri-isteri mereka menggantikan persetubuhan yang wajar dengan yang tak wajar. Demikian juga suami-suami meninggalkan persetubuhan yang wajar dengan isteri mereka dan menyala-nyala dalam berahi mereka seorang terhadap yang lain, sehingga mereka melakukan kemesuman, laki-laki dengan laki-laki, dan karena itu mereka menerima dalam

\footnotetext{
${ }^{7}$ Henry C. Thiessen,Teologi Sistematika(Jakarta:Gandum Mas,2020),19
} 
diri mereka balasan yang setimpal untuk kesesatan mereka".

Dengan tegas Allah menyebut perilaku Lesbian sebagai tindakan penyelewengan layaknya manusia yang tidak mengenal Allah sebagai penciptanya. Maka dengan melihat kasus yang ada diatas bahwa pelaku merasa nyaman dengan kondisinya seolah hal tersebut bukan suatu masalah, hal ini cukup menunjukan bahwa pelaku tidak berusaha untuk mengubah sikap demikian menjadi normal. HS dalam kasus penelitian diatas telah menolak kodrat yang Allah tentukan bagi dirinya sehingga ia telah berada dalam dosa karena menjalin hubungan dengan sesama jenis yang mana menjadi perilaku yang bertentangan dengan kodratnya yang sesungguhnya.

\section{Lesbian menentang tujuan semula penciptaan}

Dalam penciptaan sudah jelas bahwa Allah menciptakan manusia laki-laki dan perempuan, mereka diciptakan dengan perbedaan jenis kelamin dan pada saat itu memang hanya ada dua jenis yakni laki-laki dan perempuan. Tentu Allah punya maksud mengapa mereka diciptakan demikian, Allah memberkati mereka dan memberi perintah untuk menguasai ciptaan lain dan memenuhi bumi (Kej. 1:28; 9;1). Namun realisasi dari tujuan itu tidak dapat terwujud jika manusia tidak dapat bersatu yakni laki-laki dan perempuan itu, dalam hal ini jelaslah bahwa hubungan antara laki-laki dengan laki-laki demikianpun perempuan dengan perempuan tidak dapat mencapai tujuan Allah yang semula. Maka dalam menjalin hubungan dengan sesama jenis seperti kasus diatas adalah bentuk ketidaktaatan pada perintah Allah yang memiliki tujuan dalam penciptaan laki-laki dan

perempuan. Allah menyebutkan bahwa perempuan dan laki-laki adalah pasangan yang sepadan sebab mereka akan saling membantu dalam merealisasikan kehendak Allah di bumu(Kej. 2:18-25). Perilaku lesbian atau hubungan sesama jenis lainnya jelas telah menentang tujuan dari rencana Allah, hanya jika laki-laki berhubungan dengan perempuan maka tujuan tersebut dapat terwujud.

\section{Lesbian adalah kekejian bagi Allah}

Imamat 18:22 berbunyi : "Janganlah engkau tidur dengan laki-laki secara orang bersetubuh dengan perempuan, karena itu suatu kekejian". Allah benar-benar menentang terjadinya hubungan atau ketertarikan secara seksual terhadap sesama jenis baik itu homoseksual maupun Lesbian, bagi Allah perbuatan demikian adalah suatu kekejian artinya sangat tidak pantas bagi Allah. Dari ayat di atas memang yang disebutkan adalah 
laki-laki namun sebenarnya ayat di atas mencakup semua baik perempuan maupun lakilaki. Lebih dari itu dalam Imamat 20:13 mengatakan "bila seorang laki-lakitidur dengan laki-laki secara orang bersetubuh dengan perempuan, jadi keduanya melakukan suatu kekejian, pastilah mereka akan dihukum mati dan darah mereka tertimpa kepada mereka sendiri". Jika kita melihat dalam Perjanjian Lama tidak semua dosa dapat dihukum dengan hukuman mati, tetapi hanya dosa yang dianggap dosa "berat". Dengan demikian perilaku homoseksual dan lesbian adalah salah satu contoh dari dosa berat sehingga layak untuk menerima hukuman mati. Dengan demikian jelas bahwa perilaku lesbian adalah perilaku yang sangat ditentang oleh Allah karena itu Musa dengan tegas menyampaikan Firman Allah itu kepada bangsa Israel sebagai umat pilihan untuk menjaga kekudusan.

\section{Kesimpulan}

Berkaca pada Firman Allah yakni Alkitab jelaslah bahwa lesbian adalah tindakan yang bertentangan dengan kehendak Allah dan kodrat manusia sebagai ciptaan yang mulia.

Lesbian merupakan kekejian bagi Allah dan pastilah mereka yang melakukan perilaku tersebut akan mendapat hukuman. Hubungan seksual sesame jenis tidak dapat mencapai tujuan Allah dalam menciptakan manusia yaitu agar manusia agar bertambah banyak dan menguasai bumi. 


\section{Referensi}

Aziz, Safrudin, “Pendidikan Seks Perspektif Terapi Sufistik Bagi LGBT". Ernest: 2017

Novika Lusia, Sandra, Jurnal “Kontruksi Sosial Tentang Lesbian,2018

https://www.geogle.com/search?q=pengertian+lesbian+menurut+para+ahli\&oq=pengerti

$\underline{\text { an+lesbian }+ \text { para }+ \text { ahli\&aqs }=\text { chrome...69i57.7774j0j4\&client=ms-android }-}$

xiaomi\&sourceid=chrome-mobile\&ie=UTF-8. Di akses 28 April 2021.

Thiessen, Henry C., Teologi Sistematika.Jakarta:Gandum Mas,2020

Wawancara dengan DM sepupu pelaku pada tanggal 1 Mei 2021. 